\title{
The Role of Cognitive Emotion Regulation and Thought Control Strategies in the Connection between Attachment Styles and Domestic Violence in Couples
}

\author{
Kāzem Gerām \\ PhD in Psychology, Faculty Member of Azad University, Arak \\ Email:k-geram@iau-arak.ac.ir
}

Doi:10.5901/mjss.2016.v7n4s1p128

\begin{abstract}
The present study aims to investigate the role of cognitive emotion regulation and thought control strategies in the connection between attachment styles and domestic violence in couples in Arak. The population consists of married students in public and Azad universities in 2014-2015 academic years. The sample size of 361 people was estimated using Krejcie and Morgan sampling table. To have a representative sample and to prevent possible loss of participants, the sample of 380 people is selected using multistage cluster sampling method. The study is correlational. Three tools including Garnefski et al. (2001) cognitive emotion regulation, Collins \& Read's Attachment Questionnaire (1990) and domestic violence questionnaire have been used in the present study. Data were analyzed using SPSS software and Pearson's correlation coefficient method. The results showed that cognitive emotion regulation strategies and thought control strategies significantly affected the connection between attachment styles and domestic violence in student couples which led to the confirmation of the research hypothesis.
\end{abstract}

\section{Introduction}

In 1995, domestic violence was introduced as one of twelve critical issues of countries that require special attention of governments and the international communities. Domestic violence is carried out in order to dominate, control and aggression and includes psycho-emotional, physical or sexual violence. Domestic violence is defined as a behavior with overt or covert intention to physically, psychologically or socially hurt a person (Sotoodeh, 1997). Violence against women is defined as any violent sex-linked behavior that increases the risk of harmful physical, sexual or psychological damage and pain to women. Such behavior can be done with intimidation, coercion or deprivation of liberty in an overt or covert way. Men violence against women includes multiple dimensions such as physical violence (i.e. injury to one's body by beating, using hand or other tools), psychological violence (intimidation, humiliation, verbal scolding, cursing), social violence (controlling women behavior, causing social isolation, banning her communication with others) and sexual violence( calinka, 1982).

There are different perspectives to explain the causes of domestic violence. In other words, domestic violence is related to bio-environmental, psychological and sociological factors. Couples attachment style is one of the important psychological causes of the phenomenon of domestic violence and selection of such behavior by couples.

Today, attachment theory is the most widely accepted theory about emotional bonds between child and mother or babysitter. Attachment theory has been defined by John Balbi to describe that why and how children are attached to their first sitter and why when they are separated, they feel fear and get stressed. Attachment is defined as deep emotional connection with certain persons in life so that interacting with them causes the joy and happiness and whenever we get stressed, we achieve a sense of peace with them (Balbi, 1996).

From the perspective of attachment, each of the couples enter into the relationship with the expectations and experiences of their past which plays a pivotal role in response to their spouse. Therefore, the couples' problems are not only caused by the lack of communication skills but they are also due to their own early attachment experiences (Johnson, 2003). Balbi believe that attachment is an emotional bond continuing from cradle to grave. In fact, Balbi believe that the bond between the child and the sitter significantly affects the child psychological development and his behavior in adulthood. Accordingly, the mental representations of attachment that are established in childhood significantly affect attachment relationships in adulthood which will be manifested in many different forms by them (Shaver, 2006, quoting from Panahi et al., 2012). Although studies indicate that attachment styles are associated with domestic violence, but it is still unclear that how does this connection cause domestic violence precisely? Attachment styles would certainly cause to choose cognitive and emotional strategies that can reduce or increase domestic violence.

Emotion regulation is a process upon which one determines that which emotions, how, when and to what extent 
does he/she experience and express (Groth, 2002) Garnefski et al (2006) believe that mental health is caused by a mutual interaction between the use of specific types of cognitive emotion regulation strategies and correct evaluation of stressful situation and any defect in emotion regulation can make the person vulnerable in interpersonal relations and to psychological problems such as depression, anxiety.

Wells and Davis (1994) have emphasized on thought control strategies include worry, self-punishment, distraction, re-evaluation and social control in the development of meta-cognitive model of emotional disorders as one of the main components in their study. Studies show acceptable and distinctive development of these strategies (Abrahamovichn et al., 2003).

In explanation of meta-psychological problems, when maladaptive coping strategies such as preservation thought (anxiety, rumination) and avoidance and suppression of thinking are used and continued, they will increase the person's negative information about him/her. In other words, according to this theory, mental disorder is an overall cognitive syndrome that arises from the person's metacognitive knowledge and is activated and processed in problematic situations. Studies show the connection between metacognitive beliefs and emotional disorders (Ashoori and Vakili, 2009).

According to obtained data, it seems that there is a connection between attachment styles and cognitive-emotional strategies and thought control strategies and consequently domestic violence, but there is no specialized and comprehensive study on this issue. The aim of the present study is to investigate and determine the effects of cognitive emotional and thought control strategies in the connection between attachment styles and domestic violence.

\section{Methodology}

The population consists of married students in public and Azad universities in 2014-2015 academic years. The population of Arak is 6538 people. According to population size (6538 people), the sample size of 361 people is estimated using Krejcie and Morgan sampling table. To have a representative sample and to prevent possible loss of participants, the sample of 380 people is selected using multistage cluster sampling method.

\section{Research Tools}

Three different tools will be used in this study and their psychometric properties are as follows:

\subsection{Cognitive Emotion Regulation Questionnaire}

Cognitive emotion regulation questionnaire has been developed by Garnefski et al. (2001). This questionnaire is a multidimensional questionnaire and a self-report tool with 36 articles and a form for adults and children. Emotion regulation scale evaluates nine cognitive strategies including self-blaming, acceptance, rumination, positive refocusing, refocusing on planning, positive reappraisal, perspective taking, catastrophizing and blaming others Garnefski et al. have reported good reliability and validity for this questionnaire. This questionnaire contains 36 graded five-point questions (from always to never) so that every four questions evaluate one factor and a total of nine factors are evaluated including self-blaming, blaming others, catastrophizing, rumination, refocusing on acceptance planning, positive focus and positive evaluation. Persian version of this scale has been validated by Samani and Jokar (2007). In this questionnaire the participants are asked to specify their own reaction to intimidating experiences and stressful life events that they have recently experienced by responding to 5 questions that evaluate strategies to control and regulate emotion. This questionnaire has special forms for adults and children.

\subsection{Reliability and Validity}

Alpha coefficient is reported within the range of 0.71 to 0.81 for the subscales of this questionnaire by Granfsky et al (2002). For convergent-divergent validity of this questionnaire in Iran, depression, anxiety and stress scales are used which include 21 graded four-point questions (from just like me to completely different from me). In this scale each question evaluates one emotional disorder factor.

In order to evaluate psychometric properties of cognitive emotion regulation questionnaire, first this questionnaire is questioned using factor analysis method (for validation evaluation). Before factor analysis, first Kmo ratio and Bartlett's test were evaluated. After ensuring two indexes including Kmo ratio and Bartlett's Sphericity coefficient, the questions of cognitive emotion regulation questionnaire are examined using principal components method. 


\subsection{Collins and Read's Attachment Questionnaire (1990)}

This questionnaire is prepared by Collins (1990). This scale includes a self-assessment of communication skills and selfdescription of attachment relations to close attached persons, and consists of 18 data that are measured by marking on a 5-point Likert-type scale.

\subsection{Reliability and Validity}

Collins \& Read (1990), quoting from Pakdaman (2001), show that Cronbach's alpha for this questionnaire is as follows:

\begin{tabular}{ccccc}
\hline Scale & Sample & Safe & Avoidance & Ambivalent \\
\hline 173 & 0.81 & 0.78 & 0.85 \\
130 & 0.80 & 0.78 & 0.85 \\
100 & 0.82 & 0.80 & 0.83 \\
\hline
\end{tabular}

Given that Cronbach's alpha values are greater than or equal to 0.80 in all cases, the test is highly reliable. Pakdaman (2001) had evaluated this questionnaire for 100 second grade high school boys and girls who were selected randomly. The results of two times conducting this questionnaire with an interval of one month showed that this test is validated at 0.95 levels.

\subsection{Domestic Violence Questionnaire}

In this study, standard point of domestic violence against women is referred to a point that the participant gives to 71 questions of Tabrizi questionnaire.

\subsection{Reliability and Validity}

In Tabrizi study, to evaluate validity of the scale, first of all, it has been tried that items or questions that measure variables be selected from items or questions that have been conducted under the supervision of qualified persons in previous studies. Furthermore, a number of items and questions in the previous studies that were related to the issue have been selected and some other items have been added to them personally. Then by referring to professors and experts in the social sciences and using their guidance, some of the items and questions, that their accuracy was confirmed, were eventually used in the research. Cronbach's alpha coefficient was obtained 0.183 which shows that the reliability of the questions, items of the questionnaire and its different scales are sufficient.

\section{Data Analysis}

Table 1: Kurtosis and Skewness of Variables Normality Evaluation

\begin{tabular}{lcc}
\hline Variables & Skewness & Kurtosis \\
\hline cognitive emotion regulation & 0.333 & $-0 / 597$ \\
Attachment styles & -0.596 & $0 / 764$ \\
Domestic violence & -0.001 & -1.08 \\
\hline
\end{tabular}

As shown in Table 1, statistics for all above variables are ranged from -2 to +2 . So the variables are normally distributed. Therefore, this primary assumption has been observed in the present study.

Table 2: Kolmogorov - Smirnov Test for Data Normality Evaluation

\begin{tabular}{lccc}
\hline & \multicolumn{3}{c}{ Kolmogorov-Smirnov test } \\
\cline { 2 - 4 } Cognitive emotion regulation & Statistic & Degree of freedom & Significance level \\
Attachment styles & $0 / 145$ & 363 & $0 / 12$ \\
Domestic violence & $0 / 081$ & 363 & $0 / 160$ \\
\hline
\end{tabular}


According to results presented in Table 2, significance level of cognitive emotion regulation and attachment styles and domestic violence in Kolmogorov-Smirnov test are 0/12, 0/160 and 0.140, respectively. Given that significance level higher than Sig=0/05 in Kolmogorov-Smirnov test represents normality of data, so we can say that data are normally distributed.

Table 3: Correlation Coefficient of Cognitive Emotion Regulation and Attachment Styles

\begin{tabular}{ccc}
\hline Variable & Attachment styles & Significance level \\
\hline cognitive emotion regulation & $0 / 577^{* *}$ & 0.001 \\
\hline $0.01<\mathrm{P}^{* *}$ & &
\end{tabular}

According to Table 3, there is a correlation between cognitive emotion regulation and attachment styles in students $(P<0.01, R=0.577)$. Therefore, the hypothesis that there is a positive connection between cognitive emotion regulation and attachment styles in students is confirmed.

Table 4: Correlation Coefficient of Cognitive Emotion Regulation and Domestic Violence

\begin{tabular}{ccc}
\hline Variable & Domestic violence & Significance level \\
\hline Cognitive emotion regulation & $0 / 160^{* *}-$ & $0010 /$ \\
\hline $0.01<\mathrm{P}^{* *}$ & &
\end{tabular}

According to Table 4, there is a correlation between cognitive emotion regulation and domestic violence in students $(P<0.01, R=0.160)$. Therefore, the hypothesis that there is a negative connection between cognitive emotion regulation and attachment styles in students is confirmed.

\section{Discussion and Conclusions}

The present study attempted to shed light on the role of cognitive emotion regulation and thought control strategies in the connection between attachment styles and domestic violence in couples in Arak. Domestic violence is carried out in order to dominate, control and aggression and includes psycho-emotional, physical or sexual violence. Domestic violence is defined as a behavior with overt or covert intention to physically, psychologically or socially hurt a person. From the perspective of attachment, each of the couples enter into the relationship with the expectations and experiences of their past which plays a crucial role in response to their spouse. Therefore, the couples' problems are not only caused by the lack of communication skills but they are also due to their own early attachment experiences. People mental health is caused by mutual interaction between the use of specific types of cognitive emotion regulation strategies and correct evaluation of stressful situation and any defect in emotion regulation can make the person vulnerable in interpersonal relations and to psychological problems such as depression, anxiety. In the present study, the main hypothesis was tested and it indicated that cognitive emotion regulation strategies and thought control strategies significantly affect the connection between attachment styles and domestic violence in couples in Arak. This study was in agreement with those studies conducted by Nodooshan (2015), Farzanehpoor (2013), Kavianpoor (2012), Mohseni Tabrizi (2012), Vaziri (2010), Izadi (2009) as well as foreign studies conducted by Johnson (2003) and Groth (2002). The findings show that there is a significant relationship between cognitive regulation strategies and domestic violence in couples. Also, cognitive regulation strategies can reduce violence in couples due to the fact that those couples who regulate their cognitive thoughts, they will face with less violence. Cognitive regulations and thought control strategies lead to more communication and attachment between couples. Cognitive regulations and thought control significantly reduce domestic violence in couples.

\section{References}

Abrahamovichn s, kolsi w , kolin m .(2003). Examining the relationship between antecedents and women's reported level of sexual satisfaction during the first five years of marriage, 63, 452-459.

Ashoori, M., Vakili, A. (2009) .Cognitive and emotional regulation in adolescents. ( $\left.3^{\text {rd }} \mathrm{Ed}\right)$ Danjeh: Tehran

Balbi, J. (1996). Personality and temperament correlates of marital satisfaction. Journal of Personality, 67.65-88. 
Calinka, g. stive, g.(1982) 'social, attitudinal. And demographic correlates of adolescent us. College- age to bacco use in Itiation ' American journal of health behavior. Vol . 29(4) 311.323.

Groth, M. C. (2002). A narrative account of positive thinking on discussion about death and dying.3(2),78-98.

Garnefski n ,kraaij v , spinhoren ph.(2001) the relation shipbeetween cognitive coping strategies and symptoms of depression , anxiety and sociality. Aging ment heaith,1(2):166-76.

Garnefski ns , kraaij v.(2006) relation shipbeetween cognitive strategies of adolescents and depressive symptomatology across different types of life events . j youth adolesc.10(32):401-8.

Izadi, H. (2009). Comparison of the impact of patience training and problem solving training on aggression and selection of coping strategies in Police University students, Master thesis, Azad University Tehran.

Jonson ,p., rolle ,f .(2003). The role of positive and negative emotions in life satisfaction judgment across nations. Journal of Personality and Social Psychology, 95, 66-75.

Kavianpoor, M. (2012). The effectiveness of emotion-focused consulting group therapy on cognitive emotion regulation of couples in Shiraz, Master thesis, Islamic Azad University, Marvdasht branch, Faculty of Education and Psychology.

Mohseni Tabrizi, A. R., Kaldi, A. R., Javadianzadeh, M. (2012). Investigation of domestic violence in married women referred to forensic medicine center and welfare organization of Yazd in 2010, Journal of Tolou-E Behdasht-E Yazd, 11 (3), 11-24.

Nodooshan, A. (2015), Study and comparison of mental health and adjustment and cognitive emotion regulation in divorced women and married women in Yazd, Journal of Mental Health, 6, 22, 1-16.

Shaver, S. T. (2006). Violence in family, (trans. by Panahi, 2012), Tehran, Samt Publications.

Sotoodeh, M. (1997). Investigation of domestic violence, Journal of Mental Health (13 th ed.), 17, , 23, 23-37.

Vaziri, R., (2010). Investigation of the relationship between shame and dimensions of anger and comparison of this relationship among students of Tehran universities, Master thesis at Psychology, Faculty of Human Sciences, Tehran. 